health boards have not established broadly based units similar to our own. The Edinburgh experience may assist regional health authorities in England in planning the implementation of the recent recommendations of the Royal College of Physicians, ${ }^{2}$ but our results cannot be fully assessed until other units perform similar exercises.

1 Scottish Home and Health Department, Scottish Health Services Council Medical rehabilitation: the pattern for the future. Edinburgh: HMSO, 1972.

2 Royal College of Physicians. Physical disability in 1986 and beyond. $7 \mathrm{R} \mathrm{Coll}$ Physicians Lond 1986;20:160-94.

3 Garraway M. Stroke rehabilitation units: concepts, evaluation, and unresolved issues. Stroke 1985:16:178-81.
4 Smith ME. The Edinburgh Stroke Rehabilitation Study. $\mathrm{Br} f$ Occup Ther 1979;42:139-42.

5 Wright V. The epidemiology of disability. $f R$ Coll Physicians Lond 1982;16:178-83.

6 Jarman CMB. Living with stroke. Postgrad Med 7 1982.58.606-9.

7 Gardiner BM. Psychological aspects of rheumatoid arthritis. Psvchol Med 1980;10:159-63.

8 Cay EI, Vetter N, Philip A, Dugard P. Return to work after a heart attack. f Psychosom Res 1973;17:231-43.

9 Brudny J. New orthosis for treatment of hemiplegic shoulder subluxation Orthotics and Prosthetics 1985;39:14-20.

10 Maguire PA, Taylor IC, Stout RW. Elderly patients in acute medical wards factors predicting length of stay in hospital. BrMed J 1986;292:1251-3.

11 Donabedian A. The quality of medical care. Science 1978;200:856-64

12 McLachlan G. Introduction and perspective. In: McLachlan G, ed. A question of quality. Oxford: Oxford University Press, 1976:3-20.

Accepted 2 Mav 1988)

\title{
Hands across the equator: the Hereford/Muheza link
}

\section{John B Wood, Elizabeth A Hills}

Seen from an English cathedral city, Africa is far off, exotic, and unknown, its people thought to be mostly poor and in need of basic medical care. Seen from Tanzania, England is remote and alarming, its people prosperous and healthy. We two physicians, one at Hereford County Hospital and one at Hospitali Teule, Muheza, Tanzania, have tried to bring the health workers in our communities together with two aims: that each should learn something about the other's way of life, and that some practical help should be given by the richer community to the poorer one. The idea was warmly approved by the Herefordshire Health Authority and in 1985 we began to arrange visits.

Now, in 1988, the Muheza/Hereford link is securely established, and each year four health workers from each medical community visit the other for six to eight weeks. The workers already exchanged have included nurses, doctors, engineers, pharmacists, medical assistants, a dentist, and a laboratory scientist (table).

Visitors to Hereford and Muheza

\begin{tabular}{|c|c|c|}
\hline & From Muheza & From Hereford \\
\hline Sept 1985 & Senior midwifery tutor & Community dentist \\
\hline & $\begin{array}{l}\text { Senior theatre nurse } \\
\text { Seniormidwife }\end{array}$ & $\begin{array}{l}\text { Laboratory scientist } \\
\text { Radiographer }\end{array}$ \\
\hline May 1986 & $\begin{array}{l}\text { Senior midwife } \\
\text { Medical assistant (eves) }\end{array}$ & $\begin{array}{l}\text { Radiographer } \\
\text { Community nursing tutor }\end{array}$ \\
\hline Sept 1986 & $\begin{array}{l}\text { Senior nursing tutor } \\
\text { Psychiatric nurse }\end{array}$ & $\begin{array}{l}\text { Works officer (engineer) } \\
\text { Consultant obstetrician } \\
\text { and gynaecologist }\end{array}$ \\
\hline May 1987 & $\begin{array}{l}\text { Nurse anaesthetist } \\
\text { Medical assistant (paediatrics) }\end{array}$ & $\begin{array}{l}\text { Medical engineer } \\
\text { Ward sister (paediatrics) }\end{array}$ \\
\hline Sept 1987 & $\begin{array}{l}\text { Medical assistant (casualty) } \\
\text { Assistant medical officer (eyes and } \\
\text { general surgery) }\end{array}$ & \\
\hline Jan 1988 & Pharmacist & $\begin{array}{l}\text { Pharmacist } \\
\text { Theatre sister }\end{array}$ \\
\hline May 1988 & $\begin{array}{l}\text { Obstetrician and gynaecologist } \\
\text { Nursing officer (clinical instructor) }\end{array}$ & Staff nurse (intensive care) \\
\hline
\end{tabular}

\section{The two communities}

Muheza district, population 225000 , is in Tanga Province in north eastern Tanzania about $48 \mathrm{~km}$ County Hospital, Hereford HR1 2ER

John B Wood, FRCP, consultant physician

Hospitali Teule, Muheza, Tanga region, Tanzania Elizabeth A Hills, FRCP, medical superintendent

Correspondence to: $\mathrm{Dr}$ Wood. equator. The town lies below the Usumbara mountains, and the district is fertile, beautiful, and well watered. It has both a railway and a road that can be used in all weathers. Until 1980 Muheza district had separate small government and mission hospitals; they then amalgamated in new buildings and became the Hospitali Teule with eight wards and 200 beds. The Tanzanian government pays all the salaries in the hospital, and the mission and a charity in London provide Muheza with some extra resources. Hereford diocese supports one student nurse in the training school, and British medical students make "elective" visits.

Malaria and schistosomiasis are serious problems. Onchocerciasis is common in the mountains and filariasis on the plain. Many patients have diarrhoea and sexually transmitted diseases. Carcinoma of the oesophagus and the nephrotic syndrome are also common. Obstructed hernias often cause surgical emergencies, and there are many accidents and skin infections. The extent of human immunodeficiency virus (HIV) infection is not known, but usually there are three or four inpatients with clinically diagnosed AIDS at any time.

Muheza district, which has a larger population than Herefordshire, is served by Hospitali Teule, two rural health centres, and 26 dispensaries staffed by medical assistants and rural medical aids, as well as nurse/midwives and maternal and child health aids. Herefordshire is in the west of England on the Welsh border and has a population of 145000 . It has a district general hospital on two main sites in the city, a separate hospital for patients with mental diseases, one for eye diseases, seven small hospitals (each 24 to $36 \mathrm{~km}$ from Hereford) and a private hospital, as well as many general practitioners, and community nurses, midwives, and social workers.

\section{Travel and finance}

We have been given generous help by the Commonwealth Foundation (which has given over $£ 4000$ each year for travel expenses) and the Lennox Boyd Memorial Trust (which has given over $£ 2000$ ). The Herefordshire Health Authority has provided free accommodation for visitors and accounting and administrative help. In addition, at the start of the link there were small donations from several drug companies. The cost of the link, excluding the help provided by the health authority and the hospitality and kindness of individual people in Muheza and Hereford, has been held under $£ 6000$ for eight visits each year.

\section{Experiences}

Why do they go and what do they gain? Staff go for experience, to learn, to study a project, sometimes to teach, for the adventure of visiting a different culture, and also to return home with ideas for improvements. These extracts from reports and letters give a flavour of the experiences in Muheza of English staff.

A consultant obstetrician and gynaecologist - "Muheza 


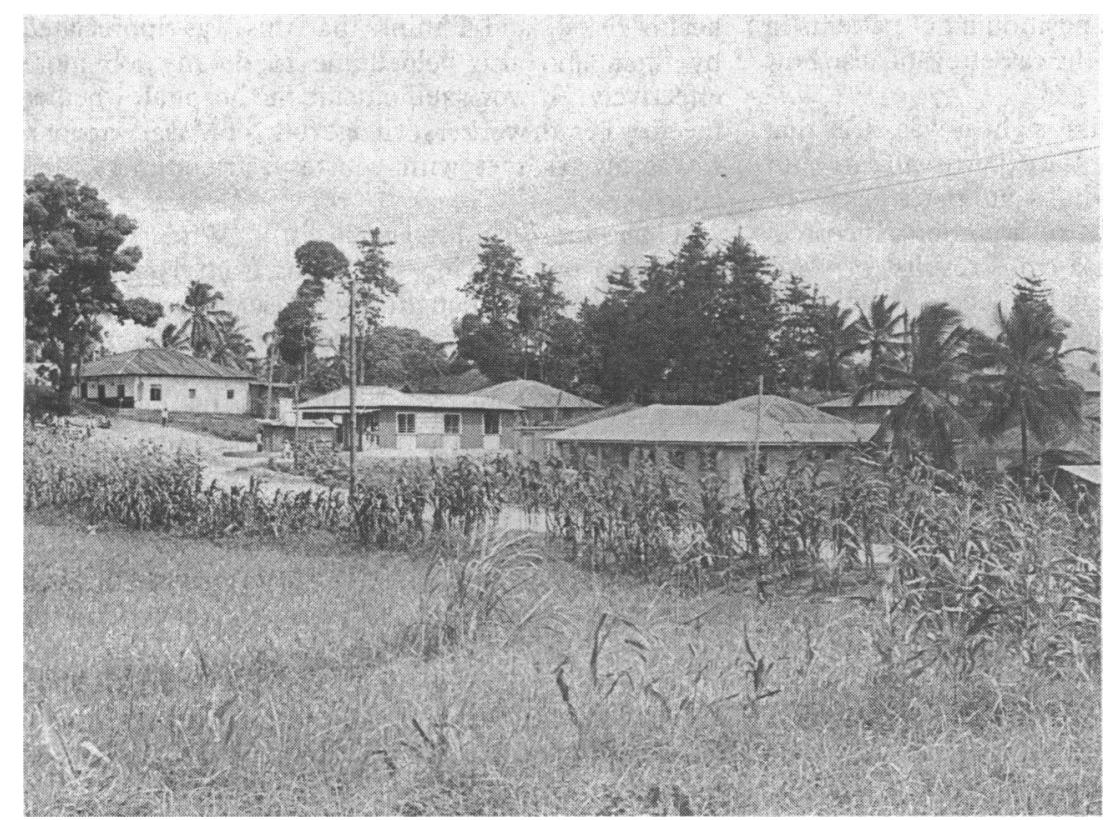

Muheza town that he had a badly deformed leg from polio. This young man had an extremely clean mouth with no sign of debris and I commented on this whereupon the little boy explained (in Swahili) that he did not want the daktari to think he had a dirty mouth so he had scrubbed himself virtually inside and out before arriving. Hence, the lateness and the dampness!"

A community nursing tutor - "The most effective way of alerting parents to our immunisation visit was by radio. In most villages there are one or two radios. From there the message is spread by word of mouth. I am sure that curiosity sometimes increased the attendances as visitors and motor vehicles were a rarity to some outlying villages. Uptake was extremely good with many parents walking great distances to attend, and we often gave more than 200 immunisations in one half day session. During these busy clinics the scene was one of generalised chaos; there is no custom of queueing. All the mothers and children crowded round and the children indulged in hysteria and tantrums as they became aware of their fate. Lack of facilities meant that there was no possibility of avoiding this upset by providing privacy for the injections, but nobody seemed to expect anything different.

"Road communication presented many challenges. On one occasion we were all terrified as the Land-rover forded a river that was flowing swiftly and swollen by the rains. On another occasion we were delayed for over an hour by a bus that had sunk into the mud that had been the road. It took a long time for the villagers and passengers to manhandle it free. By the time we arrived at the immunisation station most of our potential clients had given up and gone home.

"Facilities and equipment left much to be desired. The clinics were often held in the open air, so it was difficult to examine patients or to provide any privacy. A chronic shortage of paper meant that record keeping was limited, and continuity was difficult to maintain from one visit to the next. Needles and syringes were in short supply, and were usually boiled up on a Primus stove to resterilise them during the clinics. Disposable syringes and needles were reused many times until some needles became quite blunt. As AIDS is endemic in parts of east Africa, any failure to sterilise needles and syringes has enormous implications. For their own protection nurses should separate needles and syringes once used and place them straight into a container for resterilising, but I was appalled to see them picking up handfuls of used needles and pricking themselves in the process.

"All in all, it was rewarding to see that the community in general had such a positive attitude towards preventive health care, and a shame that lack of resources and difficult communications undermine the programme."

A radiographer-"I knew before I left England that they were desperately short of $x$ ray film so I took 60 sheets with me and they were delighted. The first patient arrived on a stretcher at 8 am for $x$ ray pictures of his lumbar spine. Everything was so different from our department at home, with only an ordinary wooden table covered with a blanket. There was no tray in which to place the cassette containing the film, so that the patient had to be lifted each time and the cassette placed directly under his body. This made accurate positioning extremely difficult. Before the next film could be taken the previous film had to be developed as there were few cassettes. This meant that one examination could take up to 30 minutes and only about 10 patients could have radiographs each day.

"When I first arrived only one machine was out of order, but during my stay the other two machines blew up. I did, however, manage to repair them both successfully, much to the amazement of my male counterparts. I was also able to help my colleagues by small face peered round. A boy of about 8 years asked if I would look at his teeth. I agreed and he came into the room. Two things were immediately obvious firstly, that he was exceedingly damp, and, secondly, 
teaching them about precise positioning of patients in relation to the $x$ ray tube and the cassette, and also how to assess a good radiograph."

A hospital engineer- "At first sight it was clear that there was neither the staff nor the expertise to carry out basic maintenance. The buildings and particularly the sewage system required a lot of attention. Incorrect electrical repairs had had disastrous results for some equipment. Much equipment had been obtained at second hand, and parts were often missing. If engineering staff could be provided regularly they could put defunct equipment back into working order that I was unable to repair and eventually could train the Tanzanians to carry out these duties themselves.

"Not long after arriving in Tanzania I learnt a lesson in acceptance of what can be regarded as normal. I was called to a broken freezer in a storeroom next to the main hospital kitchen, and we took it to the workshop for repairs. I began to dismantle it with George, a Tanzanian workman. I had just taken the cover off the compressor compartment and discovered that rats had made a nest in it and eaten most of the wiring as well as a fair proportion of the gas pipework, when a family of rats emerged and crossed the floor to one side of me. I was ready to run but felt too tired. George just pointed and I was forced to admire the shape of these rather nice looking creatures. It is amazing how far one's acceptance of things is coloured by background and experiences, and what one person perceives as normal another regards as unacceptable."

A laboratory scientist (who returned home with hepatitis $B$ infection)_- "A great deal of time was spent teaching and demonstrating, and attempting to introduce some organisation and planning to improve the laboratory work schedule. I did, for a short time, become frustrated and disillusioned by the difficulties caused by the lack of necessary supplies (something to which I slowly became accustomed) and more especially by being unable to follow sterile and safe techniques for blood handling and for sampling. The thirst for knowledge of the Tanzanian laboratory workers and their genuine desire to learn soon restored my spirits, however, and their ability to apply recently learnt skills helped me to feel that my presence was worth while.

"The days were demanding and tiring, though extremely fulfilling. At the end of them I felt that I had donated little (though that small amount was urgently required) yet I had learnt a lot. Ingenuity was more often than not the key to success. I found little problem in adapting to the simple lifestyle and was determined from the outset to integrate as much as possible with the local people and their way of life (despite certain

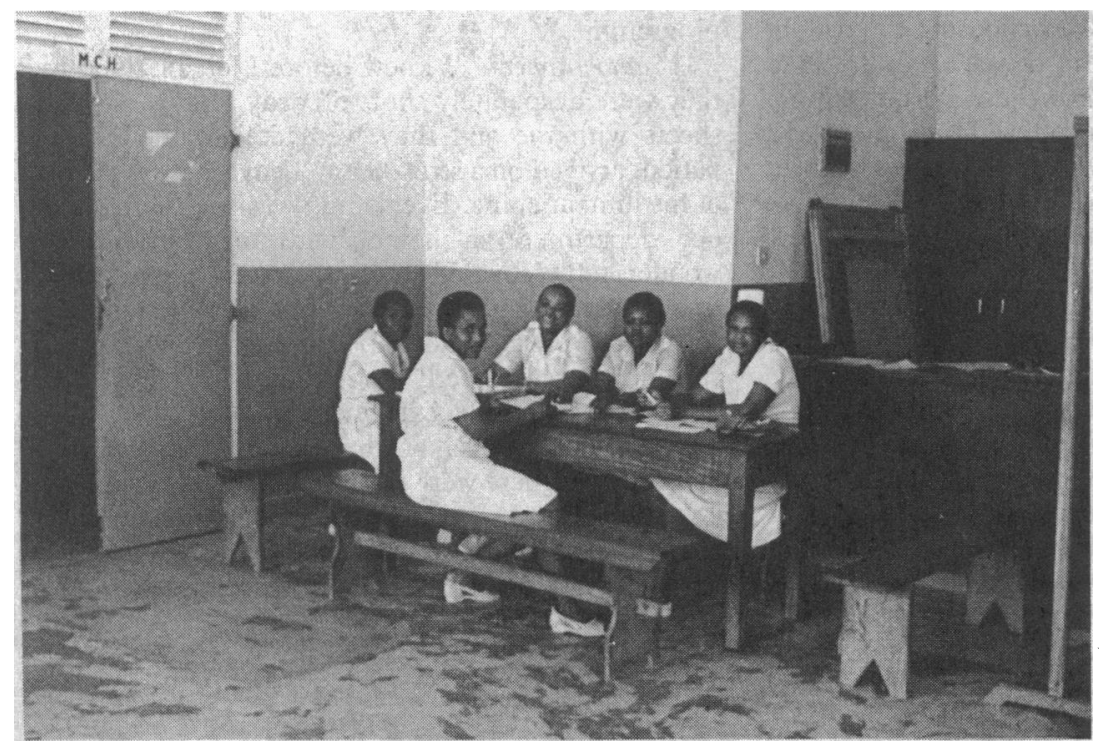

health risks), and I think that this was appreciated by them and also helped me to do my job more effectively. At work and outside the hospital, whether meeting health workers, village folk, or Masai warriors, I was always met with courtesy, friendliness, and generosity.'

A non-travelling histopathologist-_"When we knew we would be receiving specimens from Tanzania we dashed out and bought two fascicles on tropical pathology, sat back, and waited for the specimens to arrive. We rushed them into the cutting up room to see what had been sent. We quickly took the tops off the bottles and as quickly put them back on again. Perhaps we should have explained about the need for formalin fixation. The second batch were properly fixed, but this produced its own well recognised problem. Large pieces of tissue can be forced into bottles through extremely narrow necks but once fixed they cannot be extracted.

"Eighteen months and 300 specimens later we have overcome at least some of the original difficulties with fixation, bottles, and forms. The specimens themselves have been absolutely fascinating, and we have learnt many things. Academic pathologists do their best to keep the rest of us intellectually stimulated by reclassifying diseases every five years or so. Last time it was glomerulonephritis, this time lymphomas, and next time who knows or cares, but the Tanzanian experience has been a real boost to the flagging enthusiasm of approaching middle age and can be heartily recommended."

\section{Tanzanians in Hereford}

All the Tanzanian visitors spoke excellent English though only one had previously been abroad. They adjusted quickly to the change of culture-perhaps because all hospitals have certain similarities, and the main row of wards in Hereford seemed familiar because it consists of corrugated iron huts like those at Muheza, only older. The change of climate was a more difficult problem and we have tried to arrange visits in the summer. Visitors' accommodation was provided in the district general hospital.

The extent to which the Tanzanians could take part in the work of departments varied-a nursing or midwifery tutor could lecture, teach, and advise, but a medical assistant or nurse, being unregistered in Britain, could not gain practical experience.

When they returned home the Tanzanian visitors said that they had all been impressed with the hospitality they had received, and the first visitors reported of the hospital: "It was so very clean everywhere." Most were surprised that methods of treatment, delivery of babies, and the giving of anaesthetics were much the same as they were used to. Either because of their realistic approach to what they were seeing or because of the wisdom of their hosts in Hereford they did not spend their time trying to understand modern machinery that is unlikely to become available in Tanzania in the near future-for example, the medical assistant visiting the paediatric department went home with a new formula for feeding rather than details of monitors and ventilators.

As was to be expected, all came to England with a long shopping list for family and friends, usually headed by a radio cassette and including Wellington boots. Most had never expected to have the opportunity of seeing another part of the world. As one said: "It was like a dream."

\section{Changes at Muheza}

What changes have been made at Muheza as a result of the visits? There have been small changes in 


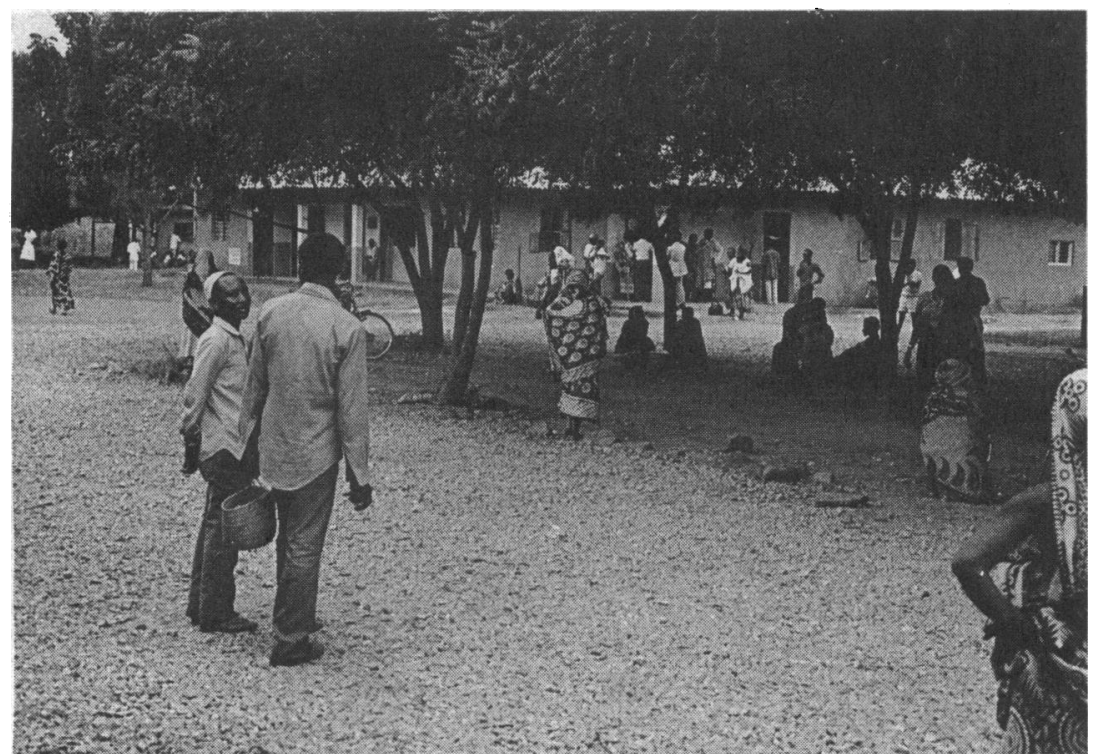

Patients waiting at the new pharmacy. Dental clinic in the same block to the left. Eye clinic in the centre

the operating theatre-a different routine for skin cleansing, the scrub nurse stands in a different place, and postoperative patients are more often placed in the recovery position.

The biggest change has resulted from the visit of a medical assistant to the casualty department. She went home with a list of requirements concerning resuscitation, but also advised that the outpatient theatre should be kept clean for suturing and resuscitation and that another dressing room should be used for incision of abscesses. These changes have been made. A dressing room has been converted, a hole knocked through the department wall, and a covered way is nearing completion that will permit trolleys to enter through an emergency entrance and to be pushed directly from the resuscitation room to the $x$ ray department and main operating theatre.

In the obstetric department a Partogram with "alert" and "action" lines is now in routine use, but its introduction met with resistance as it is not used in other schools of midwifery and the tutor was worried about lack of uniformity. We hope that it will soon be used in district dispensaries.

There have been disappointments-for example, the lack of much change in neonatal resuscitation. The number of caesarean sections increased from 90 in 1986 to 140 in 1987 without any corresponding reduction in maternal or neonatal mortality. Despite the visits of two engineers routine maintenance is forgotten, although knowledge about how to get things in working order has improved.

Perhaps we should not judge the link by the swiftness of the changes. The main aim has been that visitors in both countries should return home with new experiences, new knowledge, and ideas to discuss and perhaps to modify and to try. The Tanzanians made many friends and seemed pleased and happy to have been to Hereford. Their visits have helped to strengthen a previous link between Tanzania and the Hereford diocese, and have led to the Wye Valley Rotary Club supporting Hospitali Teule.

\section{Practical aspects of the link}

The methods of selecting the applicants have been different in the two countries. In Hereford a selection committee has tried to choose candidates who have something to offer at Muheza, who would be robust and good ambassadors, who have a project or study to perform, and who would gain from their visits. In Muheza selection has been much more democratic.
The candidates meet and each presents his or her case to the other candidates, who then vote, each having two votes.

Visitors to Muheza require immunisation against malaria, hepatitis $A$ and $B$, and thorough briefing about personal health in the tropics. They take with them their own supplies of drugs, needles, and syringes, partly to avoid using scarce resources if they become ill and also because severe shortages of equipment and supplies lead to reuse of needles and syringes that may not be adequately sterilised. The early visitor to Muheza who returned with hepatitis B infection made a full recovery.

Accommodation at Hospitali Teule is limited and most of the Hereford visitors have stayed in the student quarters. These provide basic accommodation and are often fully occupied. Adjusting to this accommodation (though it is better than that of many Tanzanians) adds to the difficulty of coping with a fundamental change of culture, climate, and work.

Among the lessons learnt is the importance of finding a friendly travel agent who will seek out cheap flights. The cheapest carrier, however, may not give the best value. We have usually used Egyptair, not quite the cheapest but reliable so far (apart from one journey). It is important to send formal invitations to Tanzanian visitors to help them to obtain leave of absence, currency, passports, and visas, and to help them through British immigration control. The cost of passports and visas must be reimbursed. Visitors should be met at the airport, and we have found it best for them to stay with one of the organisers for the first few days of each visit.

We thank particularly the directors and trustees of the Commonwealth Foundation and of the Lennox Boyd Memorial Trust, and all those in Tanzania and Herefordshire who have given help, encouragement, and hospitality. The support of the Tanzanian Ministry of Health and of the Herefordshire Health Authority and its officers has been invaluable. We are also grateful to Merrell Dow Pharmaceuticals Ltd, Sanofi UK, Ltd, Smith Kline \& French Laboratories Ltd, Leo Abbott Laboratories Ltd, Syntex Pharmaceuticals Ltd, Revlon International Corporation, and Boots Company plc, and to Miss Fiona Cameron for secretarial help. We thank all the visitors for their formal reports and the informal accounts used in this article.

(Accepled 2 June 1988)

\section{ANY QUESTIONS}

What are the hazards of crystal violet (gentian violet) preparations?

There is good evidence that crystal violet is carcinogenic in some animal species' but no information about its carcinogenicity in man. In 1987 the Department of Health advised manufacturers that products containing crystal violet should be restricted to topical application on unbroken skin to avoid possible risks of appreciable systemic absorption through broken skin and mucous membranes. The companies still marketing crystal violet preparations have received amended licences restricting their use to unbroken skin and requiring labelling to that effect.' Doctors who use the preparations outside the licensed indications must take responsibility for any adverse consequences.- LINDA BEELEY, director, Drug and Therapeutics Unit, Birmingham

1 Ministry of Agriculture, Fisheries and Food, Foxd Advisory Committee. Final report on the reciezt of the colouring matter in fond regulations 1973. London: HMSO, 1987. (FdAC RLP 4.

2 Anonvmous. DHSS puts restrictions on use of erystal violet. Pharmaceutical Joumal 1987:239:655. 